The debate about the relative roles of genes and the environment in the causation of asthma continues. While genetic influences are clearly important in atopy (although the existence of a single gene for atopy is debatable), the influence of genetic factors in asthma is less clear; most studies suggest that environmental influences are more important in converting an atopic person into an asthmatic patient. ${ }^{5}$ The quest for a single "asthma gene" is unlikely to be rewarding as a complex interplay between many genes and several environmental factors is likely to exist. The role of environmental factors such as diet and viral infections in the causation of asthma is unknown, but air pollution is unlikely to be important. $^{8}$

Recently, the management of asthma has changed substantially, and new national and international guidelines now recommend a stepwise approach to treatment. ${ }^{9}$ Fundamental to management is the early introduction of anti-inflammatory treatment rather than reliance on bronchodilators. ${ }^{10}$ Corticosteroids are by far the most effective anti-inflammatory treatment available and when inhaled are well tolerated. Inhaled steroids suppress the inflammation of asthma and effectively control symptoms in most patients. By contrast, inhaled $\beta_{2}$ agonists relieve symptoms in the short term but do not control the underlying inflammation. Indeed, it has been questioned whether excessive use of inhaled $\beta_{2}$ agonists may make asthma worse and contribute to the increased morbidity and mortality from the condition. ${ }^{11}$ This important question needs to be resolved as the number of prescriptions for inhaled $\beta_{2}$ agonists is increasing worldwide to a greater extent than the number of prescriptions for other antiasthma drugs.

We still know little about the long term outcome of asthma, and prolonged trials of treatment are needed. Early treatment of asthma with inhaled steroids gives optimal long term control, ${ }^{12}{ }^{13}$ and preliminary evidence from children suggests that delaying the introduction of inhaled steroids may result in irreversible changes to the airways. ${ }^{14}$ We need to know whether early control of asthma can "switch off" the disease; some data from adults with mild asthma suggest that this may be so..$^{15}$ Does better control of asthma in childhood reduce the risk of asthma recurring in adult life?

We need answers to these questions as asthma may account for $1-2 \%$ of the total health budget in industrialised countries. More research into basic mechanisms and careful evaluation of treatment with long term clinical trials should help to answer many of the remaining questions about this commonest of chronic diseases.

PETER J BARNES

Department of Thoracic Medicine,

National Heart and Lung Institute,

London SW3 6LY

Professor of thoracic medicine

1 Woolcock AJ, Barnes PJ. Asthma: the important questions. Part 2. Am Rev Respir Dis

1992;146:1349-66.
2 Djukanovic R, Roche WR, Wilson JW, Beasley CRW, Twentyman OP, Howarth PH, et al. Mucosal inflammation in asthma. Am Rev Respir Dis 1990;142:434-57.

3 Chung KF, Barnes PJ. Role of inflammatory mediators in asthma. Br Med Bull 1992;48:135-48

4 Robinson DS, Durham SR, Kay AB. Cytokines in asthma. Thorax 1993;48:845-53.

5 Burney PGJ. Epidemiology of asthma. Br Med Bull 1992;48:10-22.

6 Saetta M, Maestrelli P, Di Stefano A, De Marzo N, Milani GF, Pivirotto F, et al. Effect of cessation of exposure to toluene diisocyanate (TDI) on bronchial mucosa of subjects with TDI-induced asthma. Am Rev Respir Dis 1992;145:169-74.

7 Corris PA, Dark JH. Aetiology of asthma: lessons from lung transplantation. Lancet 1993;341 1369-71.

8 Magnussen $H$, Jorres $R$, Nowak $D$. Effect of air pollution on the prevalence of asthma and allergy: lessons from the German reunification. Thorax 1993;48:879-81

9 British Thorac Society. Guidelines on the management of asthma. Thorax 1993;48(suppl):S1-24.

10 Barnes PJ. Anti-inflammatory therapy in asthma. Annu Rev Med 1993;44:229-49.

11 Sears MR, Taylor DR, Print CG, Lake D, Li Q Flannery EM, et al. Regular inhaled beta-agonist treatment in bronchial asthma. Lancet 1990;336:1391-6

12 Haahtela $T$, Järvinen $M$, Kava T, Kiviranta $K$, Koskinen S, Lehtonen $K$, et al. Comparison of a $\beta_{2^{-a g o n i s t}}$ terbutaline with an inhaled steroid in newly detected asthma. $N$ Engl $f \mathrm{Med}$ 1991;325:388-92.

13 Haahtela T, Järvinen M, Kava T, Kiviranta K, Koskinen S, Lehtonen K, et al. First-line treatment of newly detected asthma: an inhaled steriod? One year's follow-up after two years' treatment. Eur Respir f 1992;5 (suppl 15):13S

14 Pedersen S, Agertoft L. Effect of long term budesonide treatment on growth, weight and lung function in children with asthma. Am Rev Respir Dis 1993;147:A265.

15 Juniper EF, Kline PA, Vanzielegmem MA, Hargreave FE. Reduction of budesonide after a year of increased use: a randomized controlled trial to evaluate whether improvements in airway responsiveness and clinical asthma are maintained. $\mathcal{F}$ Allergy Clin Immunol 1991;87:483-9.

\title{
Optimal pain relief in infants and children
}

\section{Safe methods of analgesia and anaesthesia are now available}

Until recently, infants and children commonly received insufficient pain relief. ${ }^{1}$ In some cases infants were even denied anaesthesia during surgery either because of a belief that they would not feel or remember pain or because of valid concerns regarding the safety of anaesthetic agents in sick infants. For the most part these concerns are no longer valid. In $1987 \mathrm{LeDez}$ and Lerman showed that premature neonates responded to painful stimuli and that anaesthetic agents blunted this response just as in adults. ${ }^{2}$ Safe methods of analgesia and anaesthesia are now available for infants and children of all ages.

Recent research confirms that maturation of neuroanatomical, neurophysiological, and neurochemical development of the nociceptive pathways in the central nervous system of the fetus and newborn infant is such that even preterm neonates can mount behavioural and physiological responses to noxious stimuli. ${ }^{3}$ The studies of Fitzgerald and colleagues indicate that repetitive noxious stimulation has persistent effects generating hyperalgesia with persistent increases in excitability of the spinal cord, which analgesia can prevent. $^{4}$

Assessing pain in infants is difficult. In older patients we rely primarily on verbal reports, while in infants we are forced to use behavioural and physiological variables, which are imperfect measures. For example, an infant may cry or appear distressed not only because of pain but also because of the anticipation or expectation of pain, as well as from fear or hunger. Similarly, although tachycardia and other physiological alterations may reflect pain, other conditions such as hypovolaemia, hypoxaemia, or fever may be responsible. Sophisticated analyses of infant facial expression and crying have identified specific behaviours related to pain which have been used in trials of analgesics in newborn babies and young infants. $^{5}$

Adequate pain control is important in the management of neonates and infants. Substantial humoral, metabolic, and cardiovascular responses to painful and stressful stimulation have been documented in paediatric patients of various ages during surgery and routine minor invasive or diagnostic procedures. ${ }^{6-10}$ Such responses may increase the risk of morbidity or death. ${ }^{9}$

Over the past 10 years a series of studies has confirmed the safety and efficacy of providing pain relief for infants and children with both systemic analgesics and regional blockade 
with local anaesthetics. For mild pain paracetamol seems safe even in very young infants. Data on its efficacy in young children are scarce, and dosing is based primarily on the dose that is effective for controlling fever. Several non-steroidal anti-inflammatory drugs have been shown to provide analgesia in children as young as 3. Ketorolac, ibuprofen, indomethacin, and diclofenac all reduce opioid requirements after surgery. ${ }^{11} 12$

The use of morphine in infants has been greatly feared. Recent work suggests that some of the "sensitivity" of newborn babies to morphine results from their slow metabolism of opioids; this matures by about 3 months of age. Morphine infusions provide a more steady effect than intermittent bolus administration, and they have been used safely and effectively in infants and children. ${ }^{13-15}$ In infants less than 6 months of age initial morphine infusion rates should be reduced (for example, $0.015 \mathrm{mg} / \mathrm{kg} / \mathrm{h}$ versus $0.025 \mathrm{mg} / \mathrm{kg} / \mathrm{h}$ for older infants and children). With titrated administration and an increased level of observation, morphine infusions can be used safely even in infants. Patient controlled analgesia has become extremely popular in adults because it permits the patient a sense of control and allows doses to be adjusted to individual differences. It has been shown to be extremely safe and effective in children as young as 5-7 years and may permit analgesia equivalent to continuous infusions with a smaller overall dose of morphine and fewer side effects.

Regional anaesthesia has emerged as an excellent method of pain relief in infants and children after surgery. For minor surgery peripheral nerve blockade or single shot caudal epidural blockade with the long acting local anaesthetic bupivacaine can serve as a useful adjunct to light general anaesthesia. For a child undergoing hernia repair, for example, ilioinguinal or iliohypogastric blockade can be performed either percutaneously or by the surgeon through the operative field. This approach facilitates a light plane of anaesthesia and a rapid, comfortable emergence with better analgesia and fewer side effects than with systemic analgesia.

For major thoracoabdominal or pelvic operations epidural analgesia with local anaesthetics or opioids, or both, can provide outstanding analgesia with excellent effects on pulmonary function postoperatively. Epidural analgesia is particularly useful for children with chronic respiratory disease, such as bronchopulmonary dysplasia or cystic fibrosis. ${ }^{16}$

Pain is a complex multidimensional phenomenon, and its historical undertreatment in children reflects both the nature of pain and the attitudes towards and values concerning pain and children. Unfortunately, this lack of treatment has allowed the persistence of unnecessary suffering in children, particularly in those most vulnerable-infants and chronically and critically ill children.

FREDERICK A BURROWS Associate professor of anesthesia CHARLES B BERDE

Department of Anesthesia, Associate professor of anesthesia

Harvard Medical School,

Children's Hospital,

Boston, MA 02115,

USA

1 Schechter NL. The undertreatment of pain in children: an overview. Pediatr Clin North Am 1989;36:781-94

2 LeDez KM, Lerman J. The minimum alveolar concentration (MAC) of isoflurane in preterm neonates. Anesthesiology 1987;67:301-7.

Anand KJS, Hickey PR. Pain and its effects in the human neonate and fetus. $N$ Engl F Med 1987;317:1321-9.

Fitzgerald $M$. The course and termination of primary afferent fibres. In: Wall PD, Melzack R, eds. Textbook of pain. Edinburgh: Churchill Livingstone, 1984:34.

Benini F, Johnston C, Faucher D, Aranda JV. Topical anesthesia during circumcision in newborn infants. JAMA 1993;270:850-3.

6 Anand KJS, Sippell WG, Aynsley-Green A. Randomized trial of fentanyl anaesthesia in preterm neonates undergoing surgery: effects on the stress response. Lancet 1987;i:243-8.

7 Artand KJS, Sippell WG, Schofield NM, Aynsley-Green A. Does halothane anaesthesia decrease the metabolic and endocrine stress responses of newborn infants undergoing operation? $B M \mathfrak{J}$ 1988;296:668-72.

8 Anand KJS, Hansen DD, Hickey PR. Hormonal-metabolic stress response in neonates undergoing cardiac surgery. Anesthesiology 1990;73:661-70

9 Anand KJS, Hickey PR. Halothane-morphine compared with high-dose sufentanil for anesthesia and postoperative analgesia in neonatal cardiac surgery. $N$ Engl $\mathcal{F}$ Med 1992;326:1-9.

10 Hickey PR, Retzac SM. Acute right ventricular failure after pulmonary hypertensive responses to airway instrumentation: effect of fentanyl dose. Anesthesiology 1993;78:372-6.

11 Maunuksela EL, Olkkola KT, Korpela R. Does prophylactic intravenous infusion of indomethacin improve the management of postoperative pain in children? Can $\mathcal{F}$ Anaesth 1988;35:123-7.

12 Maunuksela EL, Kokki H, Bullingham RE. Comparison of intravenous ketorolac with morphine for postoperative pain in children. Clin Pharmacol Ther 1992;52:436-43.

13 Lynn AM, Opheim KE, Tyler DC. Morphine infusion after pediatric cardiac surgery. Crit Care Med 1984;12:863-6.

14 Lynn AM, Slattery JT. Pharmacokinetics of morphine sulfate in early infancy. Anesthesiology 1985;63:A349.

15 Koren G, Butt W, Chinyanga H, Soldin S, Tan YK, Pape K. Postoperative morphine infusion in newborn infants: assessment of disposition characteristics and safety. $\mathcal{F}$ Pediatr 1985;107:963-7.

16 Ecoffey C, Dubousset AM, Samii K. Lumbar and thoracic epidural anesthesia for urologic and upper abdominal surgery in infants and children. Anesthesiology 1986;65:87-90.

\section{Clinical genetics meets primary care}

\section{Patients should benefit}

With its high technology image, clinical genetics may seem a no go subject to many general practitioners. Yet, genetic screening tests that influence general practice are developing rapidly. In this week's journal Modell describes the current state of screening for cystic fibrosis in primary care ( $p 849)$. $^{1}$

As community awareness increases, patients will expect their general practitioners to understand the implications of the new genetic tests. There may be medicolegal implications if they do not provide accurate genetic information or if they fail to refer patients. As one in 20 people will have developed evidence of a genetic condition by the age of $24,{ }^{2}$ departments of clinical genetics will clearly be unable on their own to accommodate the expected demand for genetic counselling.

Genetic services of first call will have to be based in the community. ${ }^{3}$ To achieve this two approaches have evolved; the ideal model might use both. Firstly, specialised hospital services might establish screening centres in the community, as occurred in Cyprus for the haemoglobinopathies. ${ }^{4}$ Alter- natively, primary health care teams could expand their role to include basic clinical genetic services. ${ }^{56}$ Basic educational programmes and support from genetic services need to be developed ${ }^{7}$ because general practitioners' understanding of clinical genetics may be limited. ${ }^{8}$ Without education the doctor can provide merely a patient led referral service.

The primary care approach has several advantages. Genetic counselling relies on the dissemination of accurate information through families, and general practitioners can facilitate this by knowing most members of the immediate family. It is a bonus if key members of the extended family are on the same practice list. The general practitioner's knowledge of family dynamics could help in ethical dilemmas such as when a proband blocks dissemination of genetic information to the wider family.

Opportunistic contact with the family facilitates discussion of genetic issues in both the short and the long term. As general practitioners see nearly all their patients in any five 